\title{
Development of Advanced Drill Components for BHA Using Microwave Technology Incorporating Carbide, Diamond Composites and Functionally Graded Materials
}

\author{
Final Report \\ Period Start Date: October 1, 2000 \\ Period End Date: September 30, 2002

\begin{abstract}
Authors
Dinesh Agrawal and Rustum Roy

(814)-863-8034 (Phone)

(814)-863-3617 (Fax)

Email: $\underline{\text { dxa4} @ p s u . e d u ~}$
\end{abstract}

January 2003

Contract Number DE-FC26-00NT41023

Submitting Organization(s)

Microwave Processing and Engineering Center

Materials Research Institute

The Pennsylvania State University

and

Dennis Tool Company

2020 Rankin Street, Houston 
Disclaimer:

This report was prepared as an account of work sponsored by an agency of the United States Government. Neither the United States Government nor any agency thereof, nor any of their employees, makes any warranty, express or implied, or assumes any legal liability or responsibility for the accuracy, completeness or usefulness of any information, apparatus, product or process disclosed, or represents that its use would not infringe privately owned rights. Reference herein to any specific commercial product, process, or service by trade name, trademark, manufacturer, or otherwise does not necessarily constitute or imply its endorsement, recommendation, or favoring by the United States Government or any agency thereof. The views and opinions of authors expressed here do not necessarily state or reflect those of the United States Government or any agency thereof. 


\begin{abstract}
The microwave processing of materials is a new emerging technology with many attractive advantages over the conventional methods. The advantages of microwave technology for various ceramic systems has already been demonstrated and proven. The recent developments at Penn State have succeeded in applying the microwave technology for the commercialization of $\mathrm{WC} / \mathrm{Co}$ and diamond based cutting and drilling tools, effectively sintering of metallic materials, and fabrication of transparent ceramics for advanced applications. In recent years, the Microwave Processing and Engineering Center at Penn State University in collaboration with our industrial partner, Dennis Tool Co. has succeeded in commercializing the developed microwave technology partially funded by DOE for WC/Co and diamond based cutting and drilling tools for gas and oil exploration operations.

In this program we have further developed this technology to make diamond-carbide composites and metal-carbide-diamond functionally graded materials. Several actual product of diamond-carbide composites have been processed in microwave with better performance than the conventional product. The functionally graded composites with diamond as one of the components has been for the first time successfully developed. These are the highlights of the project.
\end{abstract}




\section{Table of Contents}

$\begin{array}{ll}\text { Abstract } & 2\end{array}$

Introduction 4

Executive Summary $\quad 4$

Test Results and Tool Performance 5

$\begin{array}{ll}\text { Prototype and Commercial Systems } & 6\end{array}$

$\begin{array}{ll}\text { Carbide Diamond Composites } & 7\end{array}$

$\begin{array}{ll}\text { Compositionally Graded Composites } & 7\end{array}$

WC/Co Products and Products 8

Appendices $\quad 9$ 


\section{Development of Advanced Drill Components for BHA Using Microwave Technology Incorporating Carbide, Diamond Composites and Functionally Graded Materials}

\section{Introduction:}

The microwave processing of materials is a new emerging technology with many attractive advantages over the conventional methods. The advantages of microwave technology for various ceramic systems has already been demonstrated and proven. The recent developments at Penn State have succeeded in applying the microwave technology for the commercialization of $\mathrm{WC} / \mathrm{Co}$ and diamond based cutting and drilling tools, effectively sintering of metallic materials, and fabrication of transparent ceramics for advanced applications. In recent years, the Microwave Processing and Engineering Center at Penn State University in collaboration with our industrial partner, Dennis Tool Co. has succeeded in commercializing the developed microwave technology partially funded by DOE for WC/Co and diamond based cutting and drilling tools for gas and oil exploration operations.

The main objectives of this program have been to develop: i) an efficient and economically viable microwave processing technique to process composites of cobalt cemented tungsten carbide and diamond, ii) develop compositionally gradient system with steel and WC/Co as two end phases, and iii) develop hard metal (WC/Co), diamond and steel composites and encapsulated system without brazing - a complete tool using microwave technology.

This final report on the program provides a summary of the achievements made during the past two years of the program. The attachments of couple of published papers provide details of the results. Also hereunder are summarized the success made in commercializing the developed microwave technology for the fabrication of various products used for oil and geothermal drilling industry.

\section{Executive Summary}

Hard metal cemented tungsten carbide (WC) based composites due to their unique combination of hardness, toughness and strength, are universally used in cutting tools and 
drills, machining of wear resistant metals, mining, and geothermal drilling operations. Conventional methods for sintering WC with Co as binder involve high temperature and lengthy processing cycle (about 24 hours), and make the production cost quite high. Furthermore, such conventional conditions favor the WC grain growth. Consequently, the mechanical strength and hardness of the tool is diminished. However, microwave process does not require long processing cycle times and produces better performed product. This has been amply demonstrated on many products tested by our Industrial partner.

In the following sections, we provide summarized version of the main accomplishments under the program and the details of the same have been provided in the two published papers (Appendix).

\section{Test Results and Tool Performance:}

The microwave processed tools are not only cost effective but also have exhibited much better performance. Under the current DOE/FETC funded project, the results of the field tests performed on the commercial parts of WC/Co with/without diamond by Dennis Tool Co. showed remarkable advantage and improvement in the overall performance of microwave processed WC/Co products over the standard products. Some of the highlights of these tests are as the following:

- Wear test of microwave parts shows $20-30 \%$ increase in the performance over conventional part.

- Corrosion test by acid treatment shows that microwave processed part was 9-10 times more resistant than the conventional counterpart. Corrosion test performed on $\mathrm{WC} / 13 \% \mathrm{Co}$ substrates using nitric acid clearly showed superior resistance to the attack of the acid on the microwave sintered samples to conventional sinterHIP sample. The conventional sinter-HIP sample was extensively damaged after two days including chipping off the material, while microwave material remained intact and hardly any damage was observed. The weight loss of the microwave sintered parts was more than 7 times less than the sinter-HIP parts even including the chips that fell off the parts. The weight loss was over 19 times less when weighing only the main piece without the chips.

- Erosion test performed using dry blasting as the erosive medium and a blast spray gun with air pressure of $100 \mathrm{psi}$, showed that the microwave sintered part had about $25 \%$ better erosion resistance than the corresponding sinter-HIP parts.

- Abrasion test results also showed that microwave part was $30 \%$ better than the sinter-HIP parts.

- Hardness test results show that microwave parts are at least $10 \%$ harder than the conventional parts. 
- Microstructures of microwave sintered sample is much finer in grain size compared to the Sinter-HIP samples.

- Over all performance of microwave processed drilling inserts and roof bolt bits was much superior to the standard inserts.

- Field tests performed using microwave processed parts (including TSD composites) showed much longer life duration than the corresponding conventional parts.

In a detailed TEM investigation of microwave and conventionally sintered WC/Co samples revealed some unique and important difference in the grain boundary cementing Co phase. In the microwave sample the Co phase was found to be pure Co, and the conventional sample had about $20 \% \mathrm{~W}$ intermixed with it. This is a clear evidence of microwave effect during sintering. And also explains why microwave processed parts are superior over conventional parts in their performance and duarability. The details of this work are presented in the attached publication (Appendix I).

\section{Prototypes and Commercial Systems:}

In order to successfully commercialize the technology and conduct technologytransfer program to the interested industries, we have designed and built prototype microwave systems in the laboratory and tested their capability to produce parts with reproducible and consistent properties. Both $2.45 \mathrm{GHz}$ and $915 \mathrm{MHz}$ systems have been built. These systems were also tested for processing commercial samples of various shapes and sizes. Based on this data and design, the technology was transferred to our industrial partner (Dennis Tool Co.) for making commercial systems. They have succeeded in making several commercial units for in-house operation for manufacturing $\mathrm{WC} / \mathrm{Co}$ and $\mathrm{WC} / \mathrm{Co} /$ diamond based parts for varied applications in oil and gas industry.

Process and product development was the focus at DTC during the year for the first commercial systems in the USA. The large (3" crucible) system was supplemented with a 1.25 " crucible system to facilitate faster product development. This system can optimize and qualify product faster with more reliability. The prototypes have been accepted in the laboratory and are in the field for testing to define the product properties, costs and prices. The process conditions have been defined for the best product properties. The thermal shock resistance of the crucible components is still a problem that 
is delaying the acceptance of the large system. The materials are being upgraded and the crucible flow through the applicator has been modified to reduce thermal shock. The modifications will be qualified during the first quarter of 2003.

DTC have made three units for leading WC producers in the United States and Europe. At present Valenite and Plansee are using these systems for processing cutting and drilling tools and wear parts. At present Dennis Tool has built three systems with varying capacity and throughputs: V1.5, V3.0 and V14.2. The largest systems, V14.2 has 3.0 internal diameter of the processing tube, and capable of producing 30,000 cutting tool inserts in 24 hrs or about 12,000 rolling cone drill bit inserts. So now the newly developed microwave technology for drilling parts is well on its way into the marketplace.

\section{Carbide-Diamond Composites:}

As proposed in the original proposal, most of the tasks have been successfully accomplished in this area. The research and development of diamond composite area has progressed quite satisfactorily. Significant success in the development of laboratory type diamond composites has already been achieved. The process techniques for the thermally stable polycrystalline diamond and carbide composites have been developed, and the standard and/or custom parts are regularly manufactured at Dennis Tool Company. The initial results of the performance field tests of these parts are highly encouraging. A number of other product types such as nozzles and dies are in the prototype stages.

\section{Compositionally Gradient Composite:}

We conducted a systematic investigation of developing microwave process for making compositionally gradient composites. We succeeded to produce compositionally graded systems consisting of steel, tungsten carbide/cobalt composite, and diamond using microwave heating. We have tried various standard steel compositions with WC/Co. Only coated diamond crystals worked in our study as it is well known that uncoated diamond does not form chemical bonds in the matrix. The best sintering of the steel is obtained when using FC0208 grade steel powders. Hot pressing during microwave sintering leads to a uniform shrinkage of steel and WC/Co even with diamonds in the 
WC/Co. Cr coating covers the diamonds well, whereas Ni coating diffuses into the Co phase in the WC/Co. Large $(\sim 350 \mu \mathrm{m}) \mathrm{Cr}$ coated diamonds, and heating at $1350{ }^{\circ} \mathrm{C}$ in the microwave causes cracks in the $\mathrm{WC} / \mathrm{Co}$, whereas a temperature of $1250{ }^{\circ} \mathrm{C}$ causes no cracks. Using smaller $(\sim 55 \mu \mathrm{m}) \mathrm{Ni}$ coated diamonds results in no cracks even when sintered at $1350{ }^{\circ} \mathrm{C}$. The technical and experimental details of this work are provided in the attached publication (Appendix 2).

\section{WC/Co Products, and Prototypes:}

A summary of the products and prototype made of WC/Co and diamond at DTC, and their test results, is provided below:

1) Roof bolt bits - The first test has shown a $25-30 \%$ increase in bit life with microwave sintered carbide inserts. Seven of the ten microwave parts completed the hole while the other 3 had premature body failure. The standard bits typically do not complete even a single hole.

2) Cemented carbide inserts for roller cone bits - Another test of microwave sintered inserts verses conventionally sintered inserts has shown a noticeable increase in performance of the microwave sintered parts. Microwave and conventionally sinter HIP were alternately placed on each row of the three cones of a bit and then run. The positive result is based on a visual comparison of the parts in a one to one comparison on the same bit.

3) MW substrates for HPHT polycrystalline diamond compacts (PDC) - The PDC's are in the field and two of DTC's customers have made this their exclusive PDC product.

4) Water jet nozzles - A new product using microwave technology is being developed. A series of tests are underway with a company in Texas that uses water jet cutting machines for its production processes. To date, the nozzle has been designed and finished. The first iteration has been an improvement but the part is not yet competitive. Compositional changes are being considered.

5) Diamond composites - The thermally stable diamond (TSD) product has had some success in the market place. The market is slow and a few customers are using them at a rate of a few hundred a month.

6) Product Sale - The Dennis Tool Company sales of microwave sintered parts has impacted its sales during 2002. The carbide parts and diamond/carbide composites are being used in the oil-drilling field on a daily basis. There were over 28, 000 parts that 
were made this year at an overall price of $\$ 182,860$. This is the value of the carbide component but the actual sales of the final product can be higher. The parts are PDC substrates/backups and diamond/carbide composites for down-hole tools. The MW benefits are still present in the carbide even after being process at high temperature and pressure into a PDC.

7) The Army Research Lab has tested the cemented carbide projectiles with good results. A second set is being tested as a confirmation of the first results and more in depth analysis will be made for the potential of this material. The project will be assessed after these tests.

The qualification of the MW product into the oil and mining industry continues to be a goal of the Dennis Tool Company. The following areas are being sampled with materials and field tests: Roof bolt bits, Cemented carbide inserts for roller cone, Cemented carbide bearings. However, with the continued world economy and political problems, the drive to new developments and product risk taking is at a minimum. If this situation improves in 2003, there should be market penetration by MW sintered carbide.

\section{Appendices}

1. "Graded Steel-Tungsten Carbide/Cobalt-Diamond Systems using Microwave Heating", Dinesh Agrawal, Else Breval, J. Cheng, P. Gigl and R. Roy, in Functionally Graded Materials: Technology Leverraged Application, Compl. R. G. Ford and R.H. Hershberger, MPIF Publication, pg 50-58 (2002)

2. "Microstructural Examination by TEM of WC/Co Composites Prepared by Conventional and Microwave Processes," Dinesh Agrawal, A.J. Papworth, J. Cheng, H. Jain and D.B. William in Powder Metallurgical High Performance Materials, Proc. Vol. 2: P/M Hard Materials, Plansee Publication. Pg677-684 (2001) 


\section{Functionally Graded Materials Technology Leveraged Applications}

Proceedings of the 2002 International Conference on Functionally Graded Materials, Technology Leveraged Applications, sponsored by the Metal Powder Industries Federation in cooperation with APMI International.

Compiled by:

Renée G. Ford

Renford Communications Ltd.

Ralph H. Hershberger

TBS Group

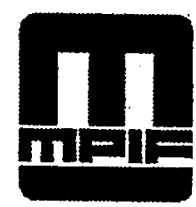

Metal Powder Industries Federation

105 College Road East

Princeton, NJ 08540-6692

Tel: (609) 452-7700 Fax: (609) 987-8523

E-mail: info@mpif.org 


\title{
GRADED STEEL-TUNGSTEN CARBIDE/COBALT-DIAMOND SYSTEMS USING MICROWAVE HEATING
}

\author{
Dinesh K. Agrawal, Else Breval, \\ Jiping Cheng, Paul Gigl. and Rustum Roy \\ Materials Research Institute \\ Materials Research Laboratory Building \\ Penn State University, University Park, PA 16802
}

\begin{abstract}
It is possible to produce compositionally graded systems consisting of steel, tungsten carbide/cobalt composite, and diamond using microwave heating. The best sintering of the steel is obtained whien using elemental iron with minor amounts of $\mathrm{Cu}$ and $\mathrm{C}$. Hot pressing during microwave sintering leads to a uniform shrinkage of steel and $\mathrm{WC} / \mathrm{Co}$ even with diamonds in the WC/Co. $\mathrm{Cr}$ coating covers the diamonds well, whereas Ni coating diffuses into the Co phase in the WC/Co. Large $(\sim 350 \mu \mathrm{m}) \mathrm{Cr}$ coated diamonds, and heating at $1350^{\circ} \mathrm{C}$ in the microwave causes cracks in the $\mathrm{WC} / \mathrm{Co}$, whereas a temperature of $1250^{\circ} \mathrm{C}$ causes no cracks. Using smaller $(\sim 55 \mu \mathrm{m})$ Ni coated diamonds results in no cracks even when using $1350^{\circ} \mathrm{C}$.
\end{abstract}

\section{INTRODUCTION}

WC/Co Material:

Tungsten carbide (WC) based composites due, to their unique combination of hardness, toughness and strength, are universally used in cutting tools and drills, machining of wear resistant metals, mining, and geothermal drilling [1].

Conventional methods for sintering WC with $\mathrm{Co}$ as a binder phase involve high temperatures (up to $1500^{\circ} \mathrm{C}$ ) and lengthy sintering cycles of the order of one day in order to achieve a high degree of sintering. Such conditions unfortunately favor undesirable WC grain growth. Consequently, the mechanical strength and hardness of the tools are diminished. It is generally recognized that finer microstructures provide superior mechanical properties and longer life of the product. Often, additives such as titanium carbide (TiC), vanadium carbide (VC) and tantalum carbide ( $\mathrm{TaC}$ ) are used to prevent grain growth of WC grains. Unfortunately such additives deleteriously affect the mechanical properties of the product [1]. 


\section{Microwave sintering of WC/Co Material}

Since microwave heating requires very little time to obtain nearly full sintering, the grain growth is relatively suppressed and a finer microstructure is generally obtained [2]. In 1991, J. P. Cheng in a $\mathrm{Ph} . \mathrm{D}$. thesis [3] first showed that WC/Co composites could be sintered in a microwave field.

In another work [4], Cheng et al. at the Penn State University were able to fully sinter WC commercial green bodies containing $12 \mathrm{wt} \%$ and $6 \mathrm{wt} \%$ Co using a newly designed microwave apparatus. They observed that microwave processed WC/Co bodies exhibited better mechanical properties than the conventional parts, fine and uniform microstructure ( 1 micron size grains) with very little grain growth, and nearly full density without adding any grain-growth inhibitors when sintered at $1250 .-1320 \mathrm{C}$ for only $10-30$ minutes [5-7].

The advantage of microwave technology can be exploited in the development of compositionally and functionally gradient materials using WC/Co, steels and diamond.

Metal powders are used in industry for diversity of products and applications. Traditional powder metallurgy is a process whereby a metal or alloy powder is compacted into a green body and then sintered to net shape at elevated temperatures. The most important metal powders in use are: iron and steel, copper, aluminum, nickel, Mo, W, WC, Sn and their alloys. It has been well recognized by the researchers that microwave heating does not work with metals and is effective only with oxide ceramics and semi-metals like carbides and nitrides. We found that the mic rowave sintering can also be applied as efficiently and effectively to powdered metals as to many ceramics [8]. Bulk metals are excellent reflectors in microwaves at room temperature and in general are not heated significantly. But in the powdered and unsintered form, virtually all metals, alloys, and intermetallics couple/heat in a microwave field very effectively to produce highly sintered bodies with improved mechanical properties. The microwave sintering of PM green bodies comprising various metals and metal alloys produced highly sintered bodies in a very short period of time [9], for example the Fe-Ni-C and Fe-Cu$\mathrm{C}$ systems. The mechanical properties such as the modulus of rupture (MOR) and hardness of microwave processed samples were much higher than the conventional samples. The densities of microwave processed samples were also higher than conventional sample.

\section{Functionally Graded Materials}

The purpose of this study is to create functionally graded materials consisting of $\mathrm{WC} / \mathrm{Co} /$ diamonds using the microwave technique. To obtain this, the following was studied:

1. the role of the steel, whether it can be used as a powder mix of elements or a powder of the steel.

2. the effect of hot pressing during microwave sintering

3. the effect of the size of diamonds

4. the effect of type of coating on the diamonds

5. the effect of the sintering temperature

\section{EXPERIMENTAL PROCEDURE}

Premixed WC with 23 and 25 wt\% Co (Hughes MPD grade 190), respectively, was used. For both qualities the WC had a particle size of 0.5 to $3.5 \mu \mathrm{m}$. The Co powder was submicron size. 
Two types of diamonds from GE were used:

Cr coated $\sim 350 \mu \mathrm{m}$ diamonds coated with $\sim 1 \mu \mathrm{m} \mathrm{Cr}$ corresponding to $\sim 3.5 \mathrm{wt} \% \mathrm{Cr}$

$\mathrm{Ni}$ coated $\sim 55 \mu \mathrm{m}$ diamonds coated with $\sim 3.6 \mu \mathrm{m} \mathrm{Ni}$ corresponding to $\sim 56 \mathrm{wt} \% \mathrm{Ni}$.

The characteristics of the steel are shown in Table 1. The phase composition was determined by Xray diffraction. The approximate amount is given as percentage of peak heights.

Table 1. Powder source of steel. Chemical analysis (in wt\%) and phases (in peak height \%) identified by X-Ray Diffraction.

\begin{tabular}{|c|c|c|c|c|}
\hline Analysis & & $\mathrm{Fe}-2 \mathrm{Cu}-0.8 \mathrm{C}$ & HSS ISO-8859-1 & 316L Stainless Steel \\
\hline Composition & $\mathrm{Fe}$ & 97.2 & 80.02 & 68 \\
\hline & $\mathrm{C}$ & 0.8 & 1.28 & 0.02 \\
\hline & $\mathbf{C u}$ & 2 & 0 & 0 \\
\hline & $\mathbf{C r}$ & 0 & 4.2 & 16.40 \\
\hline & Mo & 0 & 5.0 & 2.10 \\
\hline & $\mathbf{W}$ & & 6.4 & 0 \\
\hline & V & & 3.1 & 0 \\
\hline & $\mathbf{P}$ & & 0 & 0.03 \\
\hline & $\mathbf{S}$ & & 0 & 0.013 \\
\hline & $\mathbf{S i}$ & & 0 & 0.50 \\
\hline & $\mathbf{N i}$ & & 0 & 10.20 \\
\hline & $\mathbf{M n}$ & & 0 & 1.70 \\
\hline Phases & $\alpha$-iron & 79 & 61 & 50 \\
\hline & $y$-iron & 0 & 28 & 50 \\
\hline & Graphite & 10 & 0 & 0 \\
\hline & $\mathbf{C u}$ & 11 & 0 & 0 \\
\hline & WC & 0 & 11 & 0 \\
\hline
\end{tabular}

The samples were prepared in the form of cylinders of $\sim 8 \mathrm{~mm}$ diameter with one end consisting entirely of steel/iron powder. This layer was followed by mixtures of steel/iron powder and WC/Co with increasing amounts of $\mathrm{WC} / \mathrm{Co}$. A sample contained a total of 6 layers. (7 layers for the versions containing an additional WC/Co layer with diamonds).

The microwave sintering was carried out using a $2.45 \mathrm{GHz}$ single mode cavity. The heating rates were controlled in the range of 100 to $150^{\circ} \mathrm{C} / \mathrm{min}$ by varying the microwave input powder. An optical pyrometer was used to measure the temperature of the sample through a viewing port. All samples were sintered at temperatures ranging from $1250^{\circ} \mathrm{C}$ to $1350^{\circ} \mathrm{C}$ for 10 minutes under flowing forming gas $\left(5 \% \mathrm{H}_{2}+95 \% \mathrm{~N}_{2}\right)$.

\section{CHARACTERIZATION}

$\mathrm{X}$-ray diffractometry was carried out using an automated X-Ray Powder diffractometer PAD V, (Scintag, Santa Clara, CA) with $\mathrm{CuK}_{\alpha}$ radiation and $\lambda=1.540598 \AA$. Scans of $1^{\circ}$ per minute were employed. The intensities of the hkl reflections were calculated on the Scintag computer as areas of 
background subtracted peaks. An Olympus BX60M microscope was used for reflected light examination and a Hitachi S-3500N Scanning Electron Microscope (SEM) with an EDS attachment (PGT) was used to image and analyze polished cross sections.

Each sample was cross sectioned and polished for optical microscopy and SEM/EDS investigations. EDS investigations took place under the following conditions: $20 \mathrm{kV}, 250 \mathrm{x}$ and 50 seconds live time. For $\mathrm{W}$ and $\mathrm{Mo}$, the $\mathrm{L}_{\alpha}$ line was used, for $\mathrm{Fe}, \mathrm{Co}, \mathrm{Ni}$, and $\mathrm{Cu}$ the $\mathrm{K}_{\alpha}$ line was used.

Raman spectroscopy was carried out using an ISAU 1000 instrument using the microfocus technique.

\section{RESULTS AND DISCUSSION}

Features of the processed samples are shown in Table 2 together with X-ray diffraction results of the steel side of the composite. Individual layers made during preparation could only be observed when using $316 \mathrm{~L}$ steel, either with the naked eye or in optical microscope.

Pressureless microwaving resulted in mushrooming, whereas microwave in-situ hot pressed samples showed no mushrooming. Mushrooming means that, after sintering, the steel end was shrinking much less than the WC/Co end, which would lead to a mushroom like feature. Cracks were seen to appear only near large diamonds. Densification of the steel is demonstrated in Figure 1. The phase composition of the steel before and after microwave sintering is interesting. It seems that the presence of only the $\alpha$-iron phase leads to better densification as compared to the powders consisting of alloyed steel containing $\gamma$-iron. Figures 2 and 3 show micrographs of polished samples and Figure 4 shows the SEM/EDS analysis of the polished surface of the WC/Co with Ni coated diamonds. Both Ni and Co are distributed evenly over the WC/Co matrix.

Table 2. Visual features and phase changes of the steel phase after microwaving of composite (10 minutes). Cracks appear around larger diamonds when sintered at high temperatures. Phases in steel (in peak \%) after microwave sintering of composite ( 10 minutes). $\mathrm{C}=$ carbide alloy.

\begin{tabular}{|c|c|c|c|c|c|c|}
\hline Steel source & & Fe-2Cu-0.8C & HSS ISO- & \multicolumn{3}{|c|}{$316 \mathrm{~L}$ Stainless Steel } \\
\hline Diamonds & coating & - & - & $\mathrm{Cr}$ & $\mathrm{Cr}$ & $\mathrm{Ni}$ \\
\hline Diamonds & size & - & - & $300-400 \mu \mathrm{m}$ & $300-400 \mu \mathrm{m}$ & $50-60 \mu \mathrm{m}$ \\
\hline Temperature & & $1250^{\circ} \mathrm{C}$ & $1200^{\circ} \mathrm{C}$ & $1250^{\circ} \mathrm{C}$ & $1350^{\circ} \mathrm{C}$ & $1350^{\circ} \mathrm{C}$ \\
\hline Hot Press & $\mathbf{3 0 M P a}$ & - & - & + & + & + \\
\hline Visible layers & & - & - & + & + & + \\
\hline Mushrooming & & + & + & - & - & - \\
\hline Cracks* & & - & - & - & + & - \\
\hline Densification & (Fig. 2) & good & bad & intermediary & intermediary & intermediary \\
\hline X-ray Phases & $\boldsymbol{\alpha}$-iron & 24 & 23.5 & 0 & 0 & 0 \\
\hline & $\gamma$-iron & 59 & 53 & 100 & 100 & 25 \\
\hline & Cu & 32 & 0 & 0 & 0 & 0 \\
\hline & Graphite & 0 & 0 & 0 & 0 & 75 \\
\hline & $\mathrm{C}$ & 0 & 23.5 & 0 & 0 & 0 \\
\hline Phase changes & & $\alpha \rightarrow \alpha+\gamma$ & $\alpha+\gamma \rightarrow \alpha+\gamma$ & $\alpha+\gamma \rightarrow \gamma$ & $\alpha+\gamma \rightarrow \gamma$ & $\alpha+\gamma \rightarrow \gamma$ \\
\hline
\end{tabular}

*Cracks around diamond crystals only 


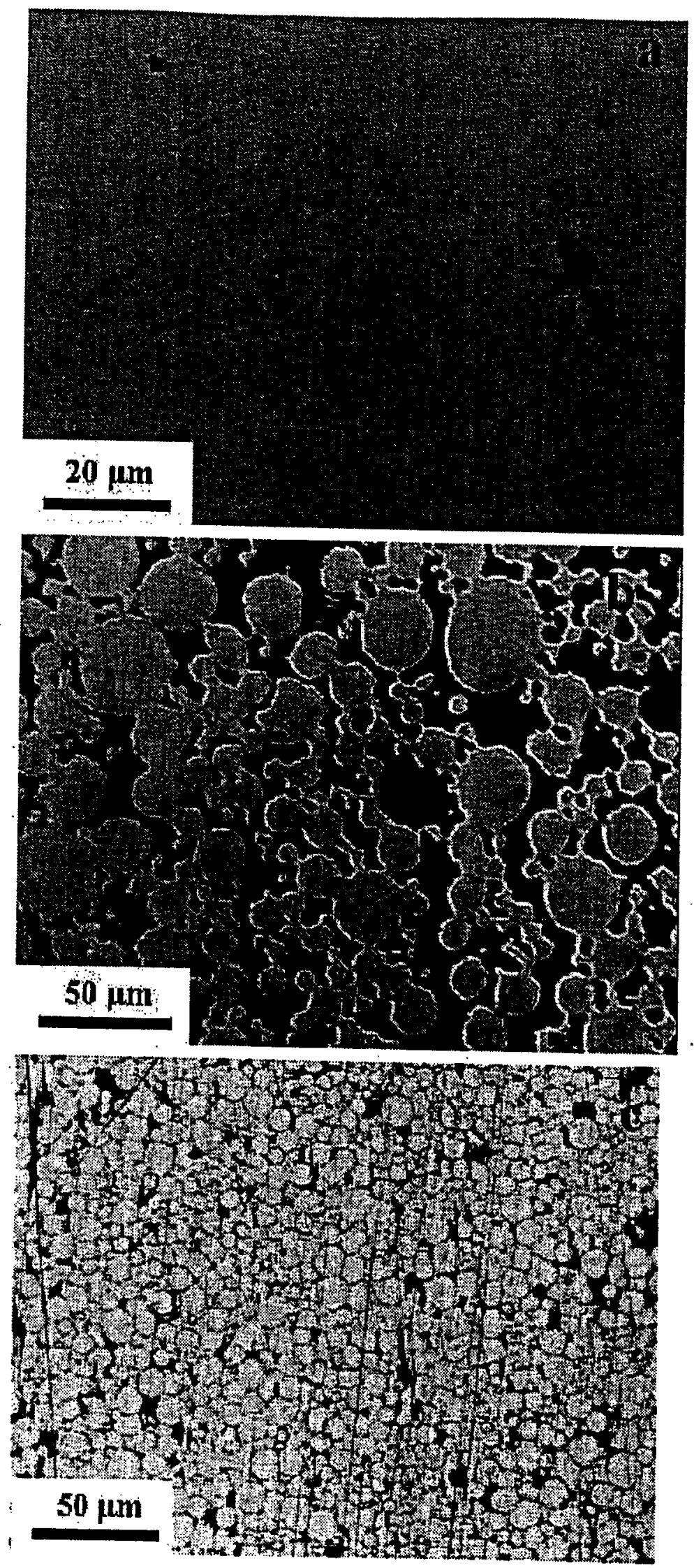

Figure 1. SEM images showing densification of the steel end of the microwaved graded material using a) the Fe-2Cu-0.8C (FC-0208), b) HSS, and c) $316 \mathrm{~L}$. 

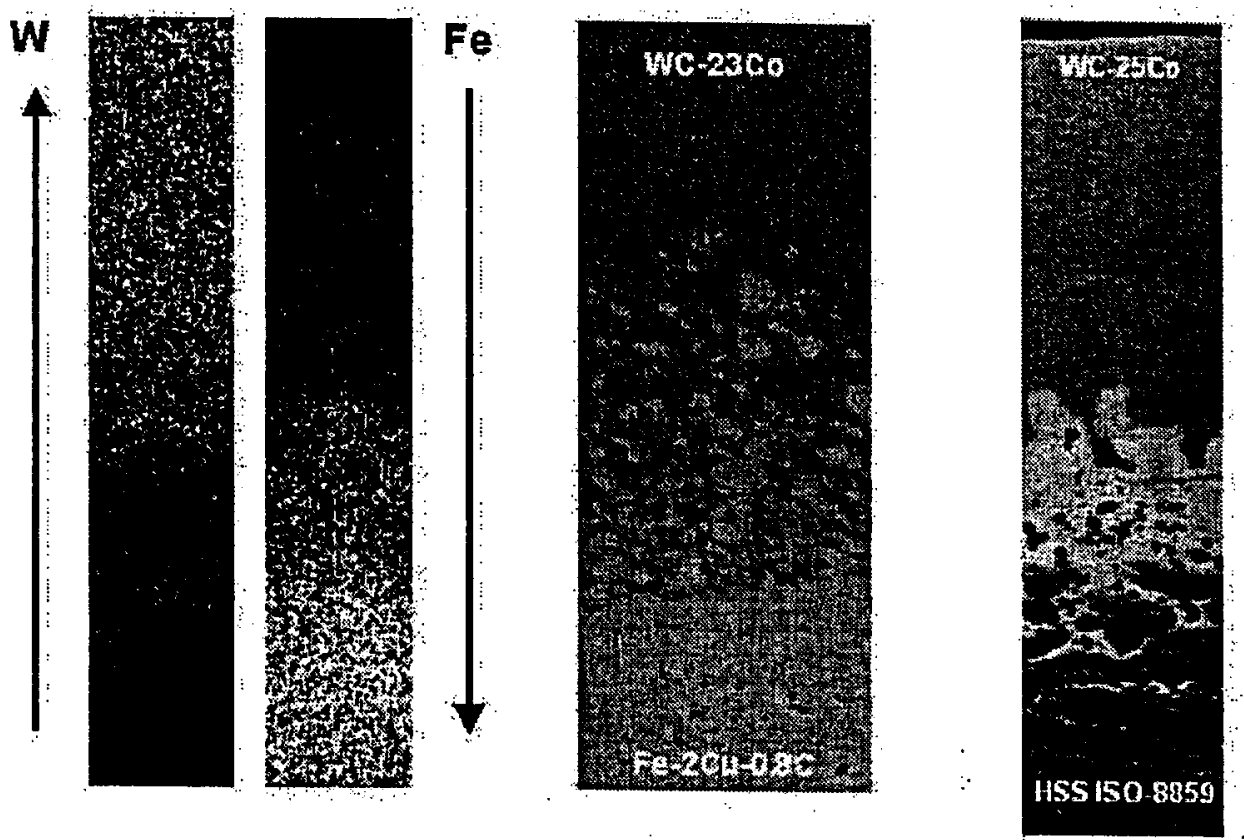

Figure 2. EDS dotmaps of the graded material showing the distribution of $\mathrm{W}$ and Fe are shown in the two images on the left; such distribution is typical of all samples. The figure also shows Optical micrographs of the graded material using the $\mathrm{Fe}-2 \mathrm{Cu}-0.8 \mathrm{C}$ and $\mathrm{HSS}$, respectively. 

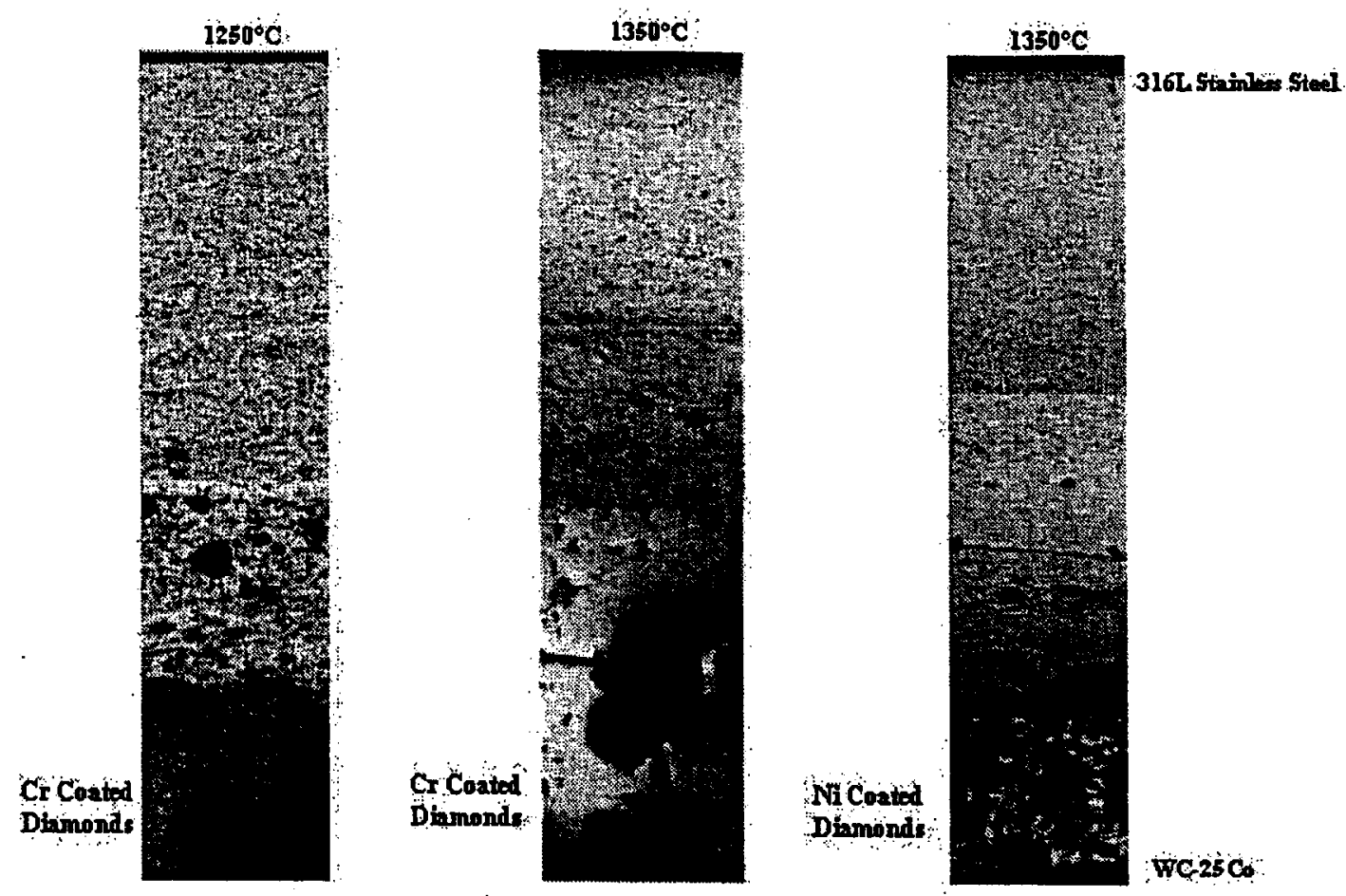

Figure 3. Optical micrographs of the graded material using the $316 \mathrm{~L}$ with diamonds in the WC/Co material for $\mathrm{Cr}$ and $\mathrm{Ni}$ coated diamonds microwave processed at different temperatures.

Raman Spectroscopy of regions containing $\mathrm{Cr}$ coated diamonds showed that it was not possible to collect a signal showing the presence of $\mathrm{sp}^{3}$ configuration (indicative of diamond), because the $\mathrm{Cr}$ coating absorbed the diamond signal. In the region between the diamond and the WC/Co only a very weak signal indicative of graphite ( $\mathrm{sp}^{2}$ configuration) was found. In the case of $\mathrm{Ni}$ coated diamond composites, there was a clear signal showing diamond. This indicates that the Ni coating had nearly disappeared from the diamond and diffused into the Co phase (Figure 4). In the region between the diamond and the $\mathrm{WC} / \mathrm{Co}$ material only a very weak signal indicative of graphite was present. 

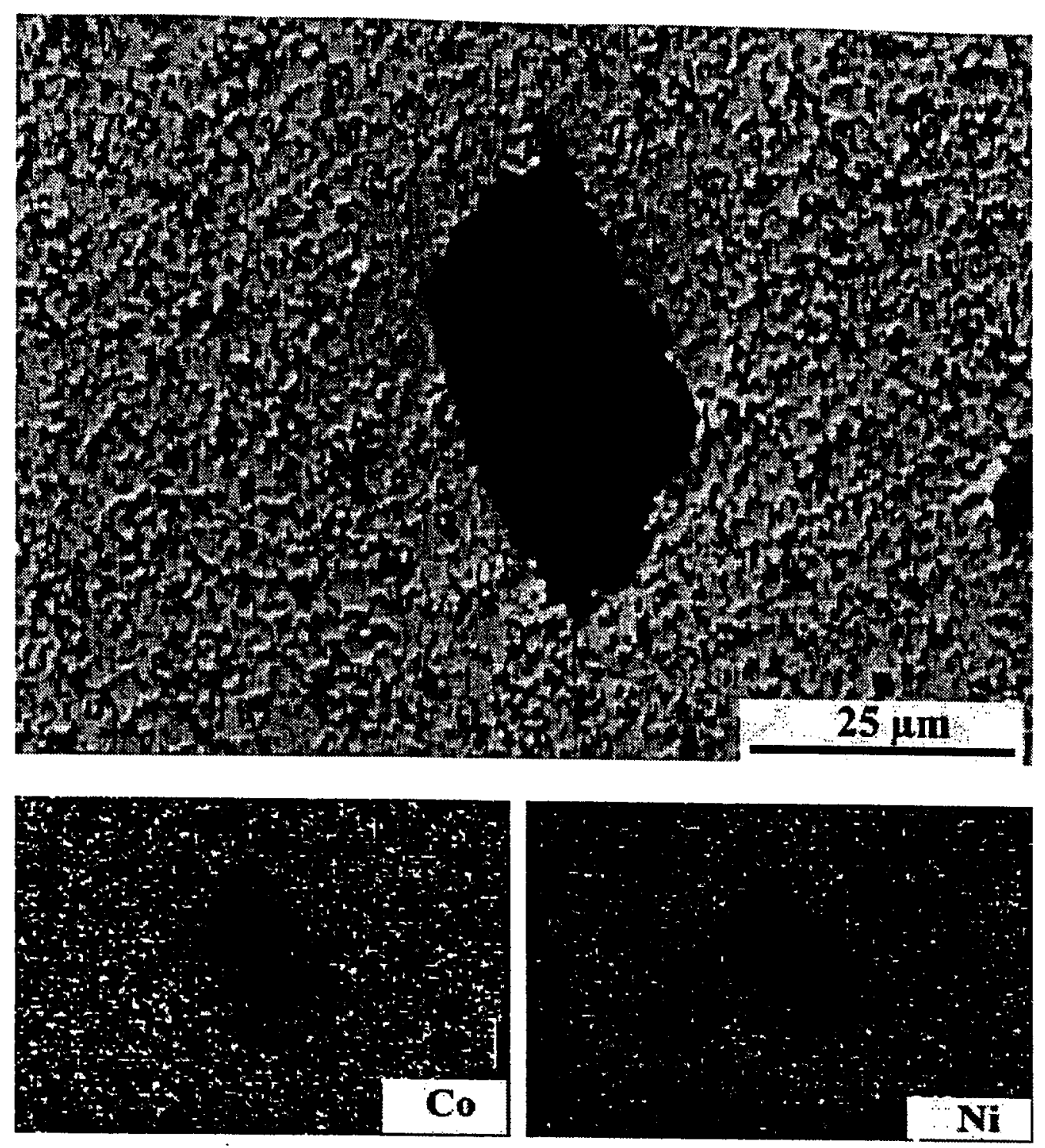

Figure 4. SEM image of the polished surface of graded material using the $316 \mathrm{~L}$ and Ni coated diamonds in the WC/Co. One of the diamonds is in the center. The EDS element dotmaps show uniform distribution of both $\mathrm{Co}$ and $\mathrm{Ni}$ in the WC/Co matrix.

\section{CONCLUSIONS}

It is possible to develop functionally graded material containing steel and WC/Co or WC/Co with diamonds.

Best sintering of the steel is obtained when using elemental iron with minor amounts of $\mathrm{Cu}$ and $\mathrm{C}$.

Hot pressing leads to a uniform shrinkage of steel and WC/Co even with diamonds in the WC/Co.

$\mathrm{Cr}$ coating covers the diamonds well, whereas $\mathrm{Ni}$ coating diffuses into the Co phase in the WC/Co.

Using large $(\sim 350 \mu \mathrm{m}) \mathrm{Cr}$ coated diamonds, and $1350{ }^{\circ} \mathrm{C}$ microwave sintering result in cracks in the $\mathrm{WC} / \mathrm{Co}$, whereas a temperature of $1250^{\circ} \mathrm{C}$ resulted in no cracks

Using smaller $(\sim 55 \mu \mathrm{m}) \mathrm{Ni}$ coated diamonds result in no cracks even at $1350^{\circ} \mathrm{C}$ 


\section{ACKNOWLEDGEMENTS}

Sponsored by DOE, project title: " Development of Advanced Drill Components for BHA Using Microwave Technology Incorporating Carbide, Diamond Composites and Functionally Graded Materials", project number DE-FC26-97FT34366.

\section{REFERENCES}

1 Paul Schwarzkopf and Richard Kieffer, Cemented Carbide, Macmillan Company, NY 1960, pp 140-160.

2 R. Roy, D. Agrawal, J.P Cheng, and M. Mathis, "Microwave processing: Triumph of Applications-Driven Science in WC-Composites and Ferroic Titanates:. Ceramic Transaction, Vol $80,1997,3-26$

3. J. Cheng, "Study on microwave sintering technique of ceramics materials." Ph.D. thesis 1991, Wuhan University of Technology, China

4. J. Cheng, D.K. Agrawal, S. Komarneni, M. Mathis, R. Roy, "Microwave processing of WC-Co composites and ferroic titanates", Mat Res Innova 1 44-52 (1997).

5. Clark DE, Tinga WR, Laia Jr JR, Microwaves: Theory and Application in Materials Processing II, Ceram Trans 1993, Vol. 36

6. R. Roy, D.K. Agrawal, J. Cheng, "An improved process and apparatus for the preparation of particulate or solid parts," U.S. patent \# 6,004,505 (Dec. 21, 1999):

7. D.K. Agrawal, J. Cheng, R. Roy, P. Seegopaul, "Microwave sintering of nanocomposite tungsten carbide-cobalt hard materials," Presented at First World Congress on Microwave Processing, January 5-9 1997, Orlando, Florida

8. R. Roy, D.K. Agrawal, S. Gedevanishvili, J. Cheng, "Full Sintering of Powdered-Metal Bodies in a Microwave Field," Nature 399 668-670 (1999).

9. T. Saji, "Method for manufacturing artificial sintered gemstone,", Japn. Patent No. 7-187760 (1995) 


\section{$15^{\text {th }}$ INTERNATIONAL PLANSEE SEMINAR

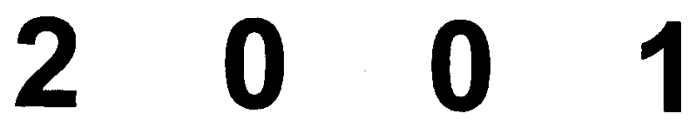

\section{Powder Metallurgical}

High Performance Materials

\section{Proceedings Volume 2: P/M Hard Materials}




\title{
Microstructural Examination by TEM of WC/Co Composites Prepared by Conventional and Microwave Processes
}

\author{
Dinesh Agrawal ${ }^{1}$, A. J. Papworth ${ }^{2}$, J. Cheng ${ }^{1}$, H. Jain ${ }^{2}$ and D.B. Williams ${ }^{2}$ \\ ${ }^{1}$ Materials Research Lab, The Pennsylvania State University \\ University Park, PA 16802 USA \\ ${ }^{2}$ Lehigh University, Department of Materials Science and Engineering, \\ Betheleham, PA 18015 USA
}

\section{Summary:}

Recently, significant developments and advances have taken place in the field of microwave processing of ceramics, composites and metals. Microwave sintering technology of WC/Co based hard metal parts has been now developed for commercial products. Microwave processed WC/Co parts reportedly have exhibited superior performance over standard parts. Additionally, the microwave process requires only one tenth of the total cycle time employed in a conventional process. Laboratory corrosion and impact resistance tests have proved that microwave processed WC/Co parts are several times more resistant than the conventional parts of the same composition. The Scanning Transmission Electron Microscopic (STEM) examination conducted on conventionally and microwave sintered WC/Co samples exhibited remarkable difference in the chemistry of cobalt binder phase. It is understood that the superior mechanical properties of microwave sintered part are due to the pure cobalt phase present at the grain boundary of WC grains, while the conventionally sintered part showed there was substantial interalloying of Co with tungsten.

\section{Keywords:}

Microwave sintering, composite, WC/Co, microstructure, TEM

\section{Introduction}

Tungsten Carbide - Cobalt (WC/Co) based hard metal composites or cemented carbides due to their unique combination of hardness, toughness 
and strength, are universally used as cutting and polishing tools, and in drilling operations underground. The production of WC/Co components involves the mixing of WC powders with cobalt binder, and then compacting the mass into a pre-sintered green body followed by the sintering. Conventional methods for sintering of WC/Co green bodies involve high temperature and lengthy sintering cycles, consequently undesirable grain growth occurs in the presence of liquid Co phase. This has adverse effect on the mechanical properties of the tool. Microwave sintering process offers an alternative method of sintering and providing finer microstructures with out using grain growth inhibitors. The technology has now been developed for cemented carbides with remarkably superior properties and overall improved
performance.

Abrasion resistance, hardness, and toughness are essential material properties for cutting tools, machining metals, tools for mining of minerals; drills for oil, gas and geothermal energy; and in countless other mechanical applications such as bearings and seals. Additionally, high corrosion and erosion resistances are important in many applications. Tradeoffs in properties such as fracture toughness and abrasion or erosion resistance can be designed into the parts by varying component materials such as cobalt content or carbide grain size. In many applications, an improvement in more than one property simultaneously is required for better performance.

Microwave heating is fundamentally different from conventional heating which involves radiant/resistance heating followed by transfer of thermal energy via conduction to the inside of the body under process. In case of microwave process it is the absorption of the microwave energy followed by volumetric heating involving a conversion of electromagnetic energy into thermal energy, which makes it instantaneous and a rapid process. Microwave absorption and heating is a function of material properties. The degree of microwave absorption and consequently heating changes dramatically with the rise in temperature. There are major potential and real advantages using microwave energy for material processing over conventional heating. Some of these advantages include: time and energy saving, very rapid heating rates $\left(>400^{\circ} \mathrm{C} / \mathrm{min}\right)$, considerably reduced processing time and temperature, fine microstructures and hence improved mechanical properties, better product performance, and selective heating.

Conventional methods for sintering WC with $\mathrm{Co}$ as a binder phase involve high temperature (up to $1500^{\circ} \mathrm{C}$ ) and lengthy sintering cycles (up to 20 hours) in order to achieve a high degree of sintering [1]. Such conditions 
unfortunately favor undesirable WC grain growth in the presence of Co liquid phase. Consequently, the mechanical strength and hardness of the tools are diminished. It is generally recognized that finer microstructures provide superior mechanical properties and longer life of the product. Often, additives such as titanium carbide (TiC), vanadium carbide (VC) and tantalum carbide (TaC) are used to prevent grain growth of WC grains. Unfortunately, besides adding to the material cost, such additives adversely affect the mechanical properties of the product as well. Since microwave heating requires very little time to obtain full densification, the abnormal grain growth and cobalt 'laking' are avoided. In 1991, J. P. Cheng in a Ph.D. thesis [2] first showed that WC/Co composites could be sintered in a microwave field. Gerdes and Willert-Porada $[3,4]$ also reported the microwave sintering of WC objects with improved mechanical properties. In another independent work [5], Cheng et al. using a newly designed microwave apparatus were able to fully sinter WC commercial green bodies containing $12 \%$ and $6 \%$ Co. They observed that microwave processed WC/Co bodies exhibited better mechanical properties than the conventional parts, finer and more uniform microstructure, and nearly full density without using any pressure or adding any grain-growth inhibitors when sintered at $1250^{\circ}-1320^{\circ} \mathrm{C}$ for only $10-30$ minutes $[6,7,8]$.

The mechanism of microwave and material interaction is not very well understood. How does microwave heating improve the mechanical properties of cemented carbide part, has not been explained yet? In this study, a comparative investigation of microwave and conventionally sintered WC/Co samples has been undertaken. Erosion, corrosion and abrasion resistance tests on both types of samples were conducted. A detailed TEM examination has been carried out toidentify the differences between the microstructures of the conventional and microwave sintered samples.

\section{Experimental}

Commercial parts of WC/Co (6 to 25 wt \% Co, Dennis Tool Co. Houston, Texas, USA) parts of various sizes ( 0.5 to 3 inch) and shapes were sintered in a microwave system operated at $2.45 \mathrm{GHz}, 6 \mathrm{~kW}$, and under ambient pressure conditions, and hydrogen atmosphere. The sintering conditions varied depending upon the amount of cobalt in the part. Typical sintering temperatures were in the range of $1350-1425^{\circ} \mathrm{C}$ and sintering time varied from 5 to 20 minutes at temperature. The total cycle time was around 1.5 hours including dewaxing. 
The erosion resistance test was performed using dry blasting medium of aluminum oxide powder. Two samples of each type were tested. The abrasion resistance test was performed using $\mathrm{SiC}$ dry grinding wheel. Volume of wheel removed was compared to the volume of carbide removed in each case. The corrosion resistance test was performed by the submersion of the carbide samples in $15 \% \mathrm{HNO}_{3}$ solution for 48 hours and determining the
weight change after the test.

Specimens for TEM study were made by manual polishing of both the microwave and conventionally sintered WC/Co composites from $3 \mathrm{~mm}$ discs to $\sim 40 \mu \mathrm{m}$. The discs were then ion-beam thinned at an angle of $4^{\circ}$, using a Gatan precision ion polishing system. The microstructural and microchemical analyses were carried out using a VG HB603 FEGSTEM with a probe size of $1.4 \mathrm{~nm}$ (FWTM) and a beam current of $0.5 \mathrm{nA}$. The STEM uses a windowless $\mathrm{Si}(\mathrm{Li})$ EDS X-ray detector with a large detector solid angle of $0.3 \mathrm{sr}$. X-ray acquisition was carried out on an Oxford (Link) exl system, where elemental windows of 7 channels wide were defined over the $\mathrm{K}_{\alpha}$ lines of $\mathrm{C}, \mathrm{O}, \mathrm{Ti}, \mathrm{Fe}, \mathrm{Co}$ and the $M_{\alpha}$ line of $W$ (the $W L_{\alpha}$ overlaps with $\mathrm{Si}$ ). Two normalizing backgrounds were defined from $3.3-3.8 \mathrm{keV}$ and $12.0-14.0 \mathrm{keV}$ respectively. X-ray maps had an acquisition time of $100 \mathrm{~ms} / \mathrm{pixel}$ with a $128 \times 128$ pixels resolution. Digital line-scans were $64 \mathrm{~nm}$ in length with a total of 64 spectra/scan. Each spectrum in the line scan had an acquisition time of $4 \mathrm{~s}$, and was normalized with respect to the background to remove the effects of thickness. Each spectrum in the line-scan had an acquisition time of 4 seconds, and was normalized with respect to the background to remove the effects of thickness. Fully quantified line-scans were obtained by taking twenty spectra, each equally spaced apart in a line crossing the PAGB. The peak intensities were then deconvoluted from each other by the simplex routine in the DTSA program. The elemental compositions were then determined using the Cliff Lorimer equation and calculated $k$ factors.

\section{Results and Discussion}

The microstructural examination of microwave sintered WC/Co samples, in general, exhibited smaller average grain size than the conventionally sintered sample. A typical microstructure of two kinds of sintered samples is illustrated in Figure 1. 
$15^{\text {th }}$ International Plansee Seminar, Eds. G. Kneringer, P. Rödhammer and H. Wildner, Plansee Holding AG, Reutte (2001), Vol. 2

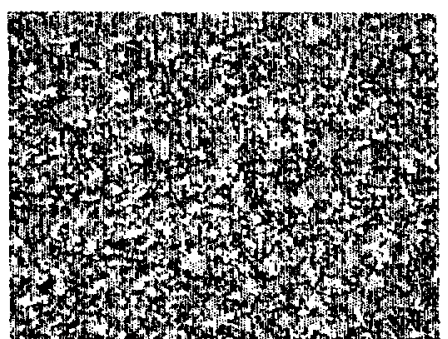

(a)

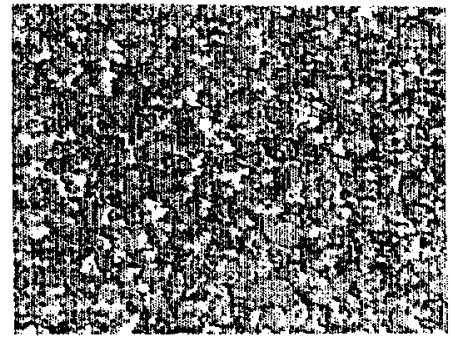

(b)

Figure 1. Microstructure of the WC/Co samples sintered in (a) microwave and (b) conventional furnaces. Note the fine grain structure, overall uniformity, and cobalt distribution in the microwave sample and the average large grain size and cobalt rich areas in the conventional sample.

Microwave sintered parts have shown significant property improvements without varying the component materials, and without the addition of grain growth inhibitors which result into lower mechanical properties. Because of this, tungsten carbide part produced by microwave sintering process exhibits an unprecedented improvement in abrasion resistance, erosion resistance, and corrosion resistance without any noticeable loss in hardness or fracture toughness.

The erosion test showed an improvement in erosion properties by $22 \%$ over the conventional part. This opens potential applications such as improved nozzle materials. The improved erosion resistance is also a desirable property in a PDC substrate material, along with improved impact strength and stress management.

The abrasion test results indicated that microwave processed sample had about 15 - $30 \%$ less weight loss as compared to sinter-HIP samples.

In acid submersion tests for the determination of corrosion resistance it was found that the average change in mass of the conventionally sintered parts was $19 \%$, while the microwave sintered parts showed an average mass change of only 1 percent, nearly a 20 times improvement. This is believed due to the fine microstructure and uniform cobalt distribution in microwave samples, that limits sites for the acid attack.

In the STEM two images can be collected at the same time. These are the ADF (Annular Dark Field) and BF (Bright Field) images. The BF is sensitive to 
mass thickness and contrast whereas the ADF image is sensitive to crystal structure and atomic number. The ADF image is very good in examining the composite structures at low magnification, and at higher magnifications the BF image is best in showing the fine details of the sample. In this study we have collected both images and studied WC/Co samples in quite detail to find out the differences in their respective microstructures.

A general analysis of WC/Co samples showed that Co phase is apparent as an interface between WC grains in two types of samples. Though, it is more uniformly distributed in microwave sintered samples. Co phase acts as a glue/binder between the WC grains. The digital line scan shows that the Co grain boundary thickness varies from 1 to $5 \mathrm{~nm}$. A line-scan through a Co/WC interface of a conventionally sintered sample shows that the $C_{0}$ is alloyed with $\mathrm{W}$. The $\mathrm{X}$-ray spectra count of conventional sample has been plotted in Figure 2 a showing that about $20 \% \mathrm{~W}$ had interalloyed with Co. The same information is more clearly seen in the line scan of WC-Co-WC structure in Figure $2 \mathrm{~b}$. On the other hand, a line-scan through a Co/WC interface in a microwave sintered sample indicates a pure Co phase with no alloying of $W$. This is illustrated in Figure 3, and Figure $4 \mathrm{a}$ and $\mathrm{b}$.

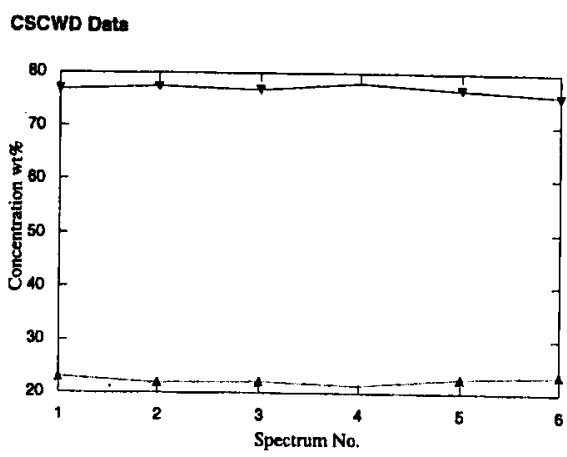

(a)

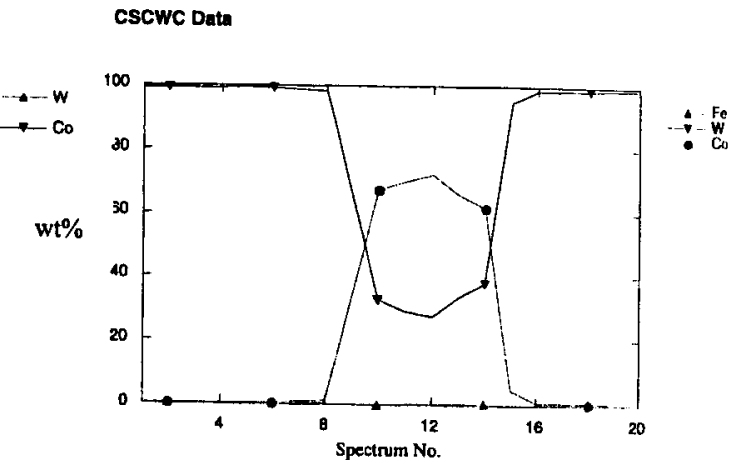

(b)

Figure 2. X-ray profile of a line scan of a conventionally sintered sample of WC/Co, showing about $20 \%$ W alloying with Co: (a) through Co/WC interface, and (b) through WC-C-WC structure. 
15 International Plansee Seminar, Eds. G. Kneringer, P. Rödhammer and H. Wildner, Plansee Holding AG, Reutte (2001), Vol. 2
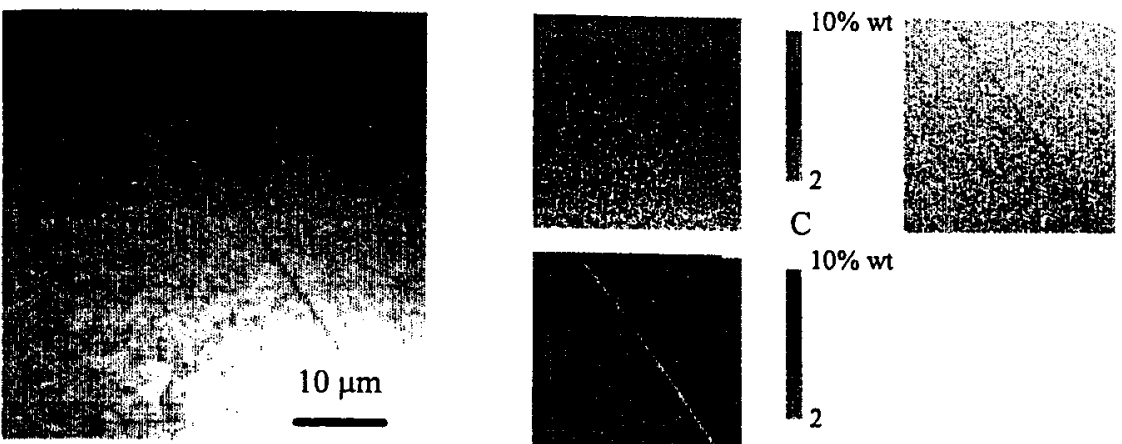

$10 \% \mathrm{wt}$
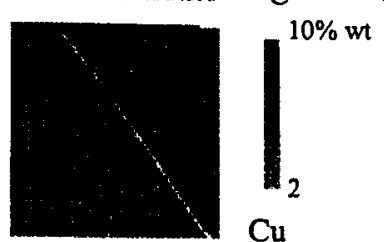

W

Figure 3. X-ray map of a WC/WC interface of a microwave sintered samples, showing the uniform and phase pure coating of Co along the interface.

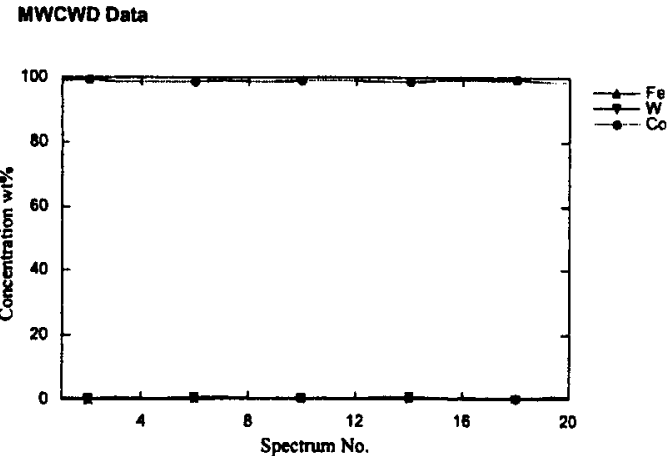

(a)

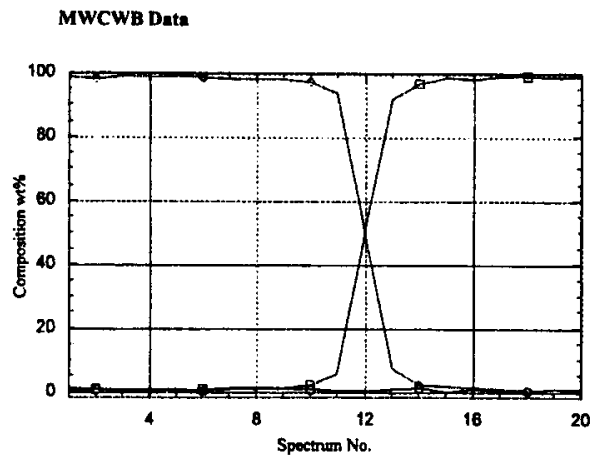

(b)

Figure 4. X-ray profile of a line scan of a microwave sintered sample of WC/Co, showing no alloying of W with $\mathrm{Co}$ : (a) through Co/WC interface, and (b) through WC-C-WC structure.

From this study, it can be concluded that the microwave sintered cemented carbide consists of pure Co phase at the WC grain boundaries, and conventionally sintered material has intermingling of Co and $W$. This also explains the earlier results of corrosion test which proved that Co was 3-4 times more strongly bonded with WC grains. 


\section{Summary}

Microwave sintering can process WC/Co composites at relatively lower temperatures and for much shorter cycle times than normally required, and produces much better mechanically performed product. The TEM investigation of the two types of samples showed that microwave samples consists of pure Co phase uniformly distributed at the grain boundaries unlike in case of conventional sample. Because of pure Co phase and its uniform distribution throughout the WC matrix the mechanical properties of the product were found to be much higher than the conventional product.

\section{References}

1. In "Cemented Carbide" by Paul Schwarzkopf and Richard Kieffer, (Macmillan Company, NY 1960), pp. 140.

2. J. Cheng: Study on microwave sintering technique of ceramics materials." Ph.D. thesis 1991, Wuhan University of Technology, China

3. T. Gerdes, M. Willert-Porada: Mat Res Soc Symp Proc, 1994, Vol. 347, pp. 531-537

4. T Gerdes, M. Willert-Porada, K. Rodiger: Mat Res Soc Symp Proc.1996, Vol. 430, pp. 45-50

5. J. Cheng, D.K. Agrawal, S. Komarneni, M. Mathis, R. Roy: Mat Res Innova, 1997, Vol. 1, pp. 44-52

6. P.D. Gigl, E. Breval, J. Cheng, D.K. Agrawal, R. Roy, "Structure properties of microwave sintered cemented tungsten carbide materials", Presented at First World Congress on Microwave Processing, January 5- -9 1997, Orlando , Florida

7. R. Roy, D.K. Agrawal, J. Cheng, "An improved process and apparatus for the preparation of particulate or solid parts," U.S. patent \# 6,004,505 (Dec. 21, 1999).

8. D.K. Agrawal, J. Cheng, R. Roy, P. Seegopaul, "Microwave sintering of nanocomposite tungsten carbide-cobalt hard materials," Presented at First World Congress on Microwave Processing, January 5-9 1997, Orlando, Florida 